\title{
Analisa dan Perancangan Sistem Informasi Pengolahan Data Pegawai Pada Kantor Satuan Polisi Pamong Praja
}

\author{
Ferry Prasetyo \\ Bina Sarana Informatika \\ Jl. Cut Meutia No. 88, Bekasi, Jawa Barat 17114 \\ feriphd@gmail.com
}

\begin{abstract}
Office of Civil Service Police Unit Pangkalpinang formed in order to carry out the duties of government field Enforcing Regulation (Regulation), which is led by a Head of the Office of the Mayor Pangkalpinang jawan held by the Regional Secretary. Office of Civil Service Police Unit Pangkalpinang is located at $\mathrm{Jl}$. Diamond Stone Village Girimaya Pangkalpinang. Office of Civil Service Police Unit Pangkalpinang have some technical areas and sub-sections. Here will be discussed regarding employee data processing system consisting of employee data collection in and out through the process of moving staff, The process of making DP3 (List of Work Implementation Assessment), the process of making a Certificate of Family Allowances To Get Payments (KP4), periodic employee payroll process, the process of recording training and reporting process. All data processing personnel in the Office of Civil Service Police Unit Pangkalpinang relate to the Regional Employment Board and the Department of Revenue, Finance and Asset Management Regional Pangkalpinang.
\end{abstract}

Keywords-- Office of Civil Service Police Unit Pangkalpinang and Employee Data Processing System

\section{PENDAhUluan}

Penerapan sistem informasi pada suatu instansi pemerintah maupun swasta sangat dibutuhkan karena perkembangan teknologi yang sangat pesat menuntut suatu instansi untuk memperoleh informasi yang lebih cepat dan akurat.

Sistem Informasi dibuat untuk mempermudah dalam pengelolaan dan penyimpanan data maka dapat menghasilkan suatu informasi yang tepat dan akurat. Adanya sistem informasi yang tepat dan akurat dapat mengurangi terjadinya kesalahan yang tidak diinginkan sehingga dapat meningkatkan kinerja yang lebih efisien dan kecepatan operasional instansi.

Kantor Satuan Polisi Pamong Praja memiliki banyak data yang salah satunya yaitu data kepegawaian yang perlu untuk disimpan dan diolah. Apalagi di era pemerintahan dengan konsep Good Governance ini diperlukan adanya sistem yang mampu mengakomodir kebutuhan akan pelayanan yang cepat, tepat dan tidak berbelit-belit.

Dengan penggunaan sistem informasi,dimungkinkan adanya otomatisasi pekerjaan dan fungsi pelayanan untuk mewujudkan pelayanan yang baik seperti yang dibutuhkan, termasuk otomatisasi dalam penanganan sistem kepegawaian. Untuk itulah dibuat Analisa dan Perancangan Sistem Informasi Pengolahan Data Pegawai sehingga menghasilkan informasi yang berguna bagi bagian kepegawaian dan pegawai itu sendiri.

\section{LANDASAN TEORI}

\section{A. Konsep Dasar Sistem Informasi}

sistem informasi adalah suatu sistem di dalam suatu organisasi, yang mempertemukan kebutuhan pengolahan transaksi harian, mendukung operasi, bersifat manajerial dan kegiatan strategi dari suatu organisasi dan menyediakan pihak luar tertentu dengan laporan-laporan yang diperlukan [1].

sistem informasi juga merupakan sekumpulan prosedur organisasi yang pada saat dilaksanakan akan memberikan informasi bagi pengambil keputusan dan atau mengendalikan organisasi [2].

\section{B. Unified Modelling Languange}

UML adalah bahasa nyata (grafis) yang menggambarkan, menetapkan, membangun, dam mendokumentasikan sesuatu (benda) pada sebuah system perangkat secara intensif) [4]. Seperti bahasa lainnya, UML mendefinisikan notasi dan sintaksis/ semantik. Notasi UML merupakan sekumpulan bentuk khusus untuk menggambarkan berbagai diagram software. Setiap bentuk memiliki makna tertentu, dan sintaksis UML mendefinisikan bagaimana bentuk-bentuk tersebut dapat didefinisikan.

\section{Analisa Sistem Berorientasi Objek}

Analisa system berorientasi objek adalah tahap menentukan kebutuhan perangkat lunak, yang mendaftarkan apa pun yang harus dipenuhi oleh sistem software, bukan 
mengenai bagaimana sistem software melakukannya[3]. Yang dilakukan dalam analisa berorientasi objek adalah mempelajari domain permasalah, kemudian menghasilkan spesifikasi dari tingkah laku eksternal yang diamati akan mempengaruhi dan mendukung domain perusahaan.

\section{Metode PENELITIAN}

Dalam penyusunan penelitian ini untuk mencapai tujuannya digunakan beberapa metode penelitian yang mendukung diantaranya yaitu :

\section{A. Studi Kepustakaan}

Metode penelitian dengan mempelajari buku-buku maupun bahan-bahan tertulis yang terkait dengan penelitian ini.

\section{B. Studi Lapangan}

Metode penelitian dengan mengadakan peninjauan langsung pada Kantor Satuan Polisi Pamong Praja Kota Pangkalpinang. Metode penelitian yang digunakan antara lain:

1) Pengamatan (Observation)

$\begin{array}{lccc}\text { Pengumpulan } & \text { data dilakukan dengan cara } \\ \text { mendatangi } & \text { secara } & \text { langsung bidang } \\ \text { kepegawaian } & \text { Kantor } & \text { Satuan Polisi Pamong }\end{array}$ Praja Kota Pangkalpinang dan melakukan pengamatan terhadap sistem berjalan.

2) Wawancara (Interview)

Pengumpulan data dilakukan dengan mengadakan tanya jawab secara langsung dengan pihak-pihak terkait untuk memperoleh gambaran secara umum tentang sistem kepegawaian dan masalah-masalah yang berkaitan dengan penelitian.

3) Dokumentasi (Documentation)

Pengumpulan data dengan cara mempelajari dokumentasi tertulis yang berkaitan dengan sistem informasi kepegawaian.

\section{Proses Bisnis}

Dalam menyajikan permasalahan yang ada pada sistem manual maka perlu diketahui proses-proses apa saja yang akan terjadi di instansi dalam kegiatan sehari-hari agar dapat menganalisa setiap proses. Berikut proses sistem berjalan pada Kantor Satuan Polisi Pamong Praja Kota Pangkalpinang :

1) Proses Mutasi Pegawai

Proses pendataan pegawai masuk dan keluar pada

Kantor Satuan Polisi Pamong Praja Kota Pangkalpinang yaitu Bagian Kepegawaian Kantor Satuan Polisi Pamong Praja Kota Pangkalpinang menerima SK mutasi dari Badan Kepegawaian Daerah (BKD) lalu Bagian Kepegawaian menyerahkan SK mutasi ke Pegawai.

2) Proses Surat Keterangan Untuk Pembayaran Tunjangan Keluarga (KP4)

Pegawai memberikan data-data untuk membuat Surat Keterangan Untuk Pembayaran Tunjangan Keluarga (KP4) kepada Bagian Kepegawaian. Lalu Bagian Kepegawaian mengetik data-data yang diberikan pegawai dan diserahkan kepada pegawai untuk ditandatangani. Setelah ditandatangani diserahkan kembali kepada Bagian Kepegawaian. Lalu Bagian Kepegawaian menyerahkan kepada Kepala Kantor Satuan Polisi Pamong Praja Kota Pangkalpinang untuk ditandatangani dan diserahkan kembali kepada Bagian Kepegawaian dan Bagian Kepegawaian mengirimkan Surat Keterangan Untuk Pembayaran Tunjangan Keluarga (KP4) kepada Dinas Pendapatan, Pengelolaan, Keuangan dan Aset Daerah (DPPKAD) Kota Pangkalpinang.

3) Proses Pendidikan dan Pelatihan Pegawai

Bagian Kepegawaian membuat Surat Perintah Tugas untuk mengikuti pendidikan dan pelatihan yang akan diserahkan ke Pegawai. Kemudian setelah selesai mengikuti pendidikan dan pelatihan Pegawai melaporkan kepada Bagian Kepegawaian bahwa pendidikan dan pelatihan telah selesai dan menyerahkan Surat Tanda Tamat Pendidikan Dan Pelatihan.

4) Proses Kenaikan Gaji Berkala

Bagian Kepegawaian membuat surat Kenaikan Gaji Berkala dan menyerahakhan kepada Kepala Kantor Satuan Polisi Pamong Praja Kota Pangkalpinang untuk disetujui dan ditandatangani, setelah disetujui dan ditandatangani Kepala Kantor Satuan Polisi Pamong Praja Kota Pangkalpinang menyerahkan surat kenaikan gaji berkala kepada Bendaharawan Gaji Satuan Polisi Pamong Praja Kota Pangkalpinang. Bendaharawan Gaji Satuan Polisi Pamong Praja Kota Pangkalpinang menyerahkan surat Kenaikan Gaji Berkala ke Dinas Pendapatan, Pengelolaan, Keuangan dan Aset Daerah (DPPKAD) Kota Pangkalpinang.

5) Proses Daftar Penilaian Pelaksanaan Pekerjaan (DP3) Pegawai Negeri Sipil.

Bagian Kepegawaian menyerahkan formulir DP3 ke atasan langsung masing - masing pegawai, atasan langsung menerima formulir DP3 dan mengisi formulir DP3 dan memberikan nilai. Selanjutnya formulir DP3 yang telah diisi nilai diserahkan ke bagian kepegawaian untuk diketik, 
setelah selesai DP3 diketik diserahkan kembali ke atasan langsung masing-masing pegawai untuk ditandatangani. Kemudian DP3 yang telah ditandatangani diserahkan lagi ke bagian kepegawaian, kemudian DP3 yang telah terkumpul dikirim ke Badan Kepegawaian Daerah (BKD) Kota Pangkalpinang.

6) Proses Pembuatan Laporan Daftar Urut Kepangkatan (DUK)

Bagian Kepegawaian membuat Laporan Daftar Urut Kepangkatan (DUK) setiap akhir tahun berdasarkan data pegawai dan diserahkan kepada Kepala Satuan Polisi Pamong Praja Kota Pangkalpinang untuk ditandatangani. Laporan pegawai yang sudah ditandatangani tersebut diserahkan kembali kepada Bagian Kepegawaian. Kemudian Bagian Kepegawaian menyerahkan Laporan Daftar Urut Kepangkatan (DUK) kepada Badan Kepegawaian Daerah (BKD).

\section{Hasil Dan Pembahasan}

\section{A. Use Case Diagram}

\section{1) Use Case Diagram Master}

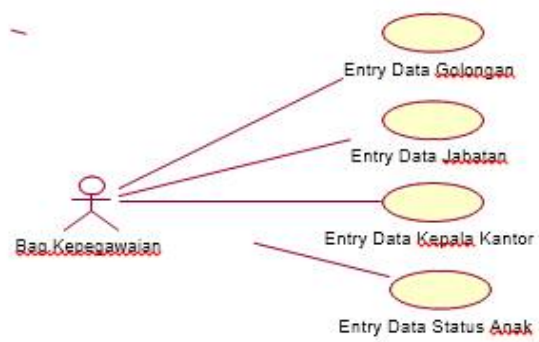

Gambar 1. Use Case Diagram Master

2) Use Case Diagram Transaksi

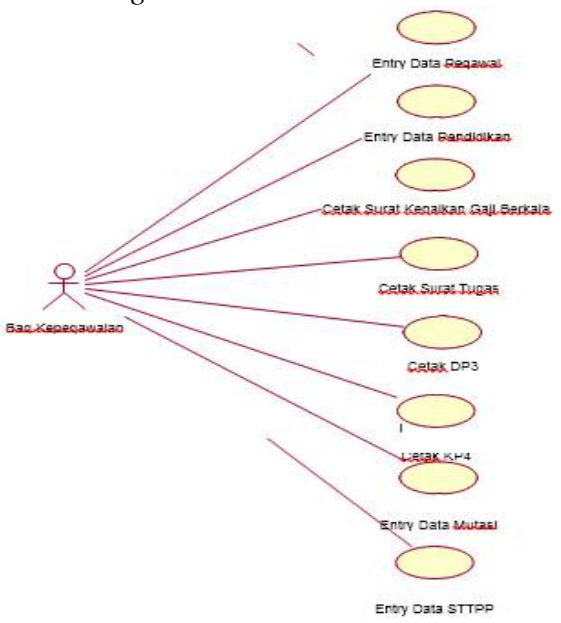

Gambar 2. Use Case Diagram Transaksi
3) Use Case Diagram Laporan

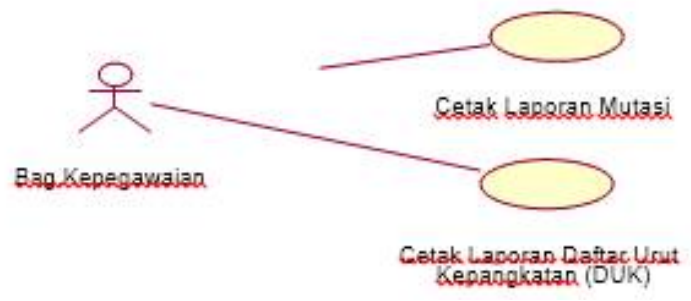

Gambar 3. Use Case Diagram Laporan

B. Entity Relationship Diagram

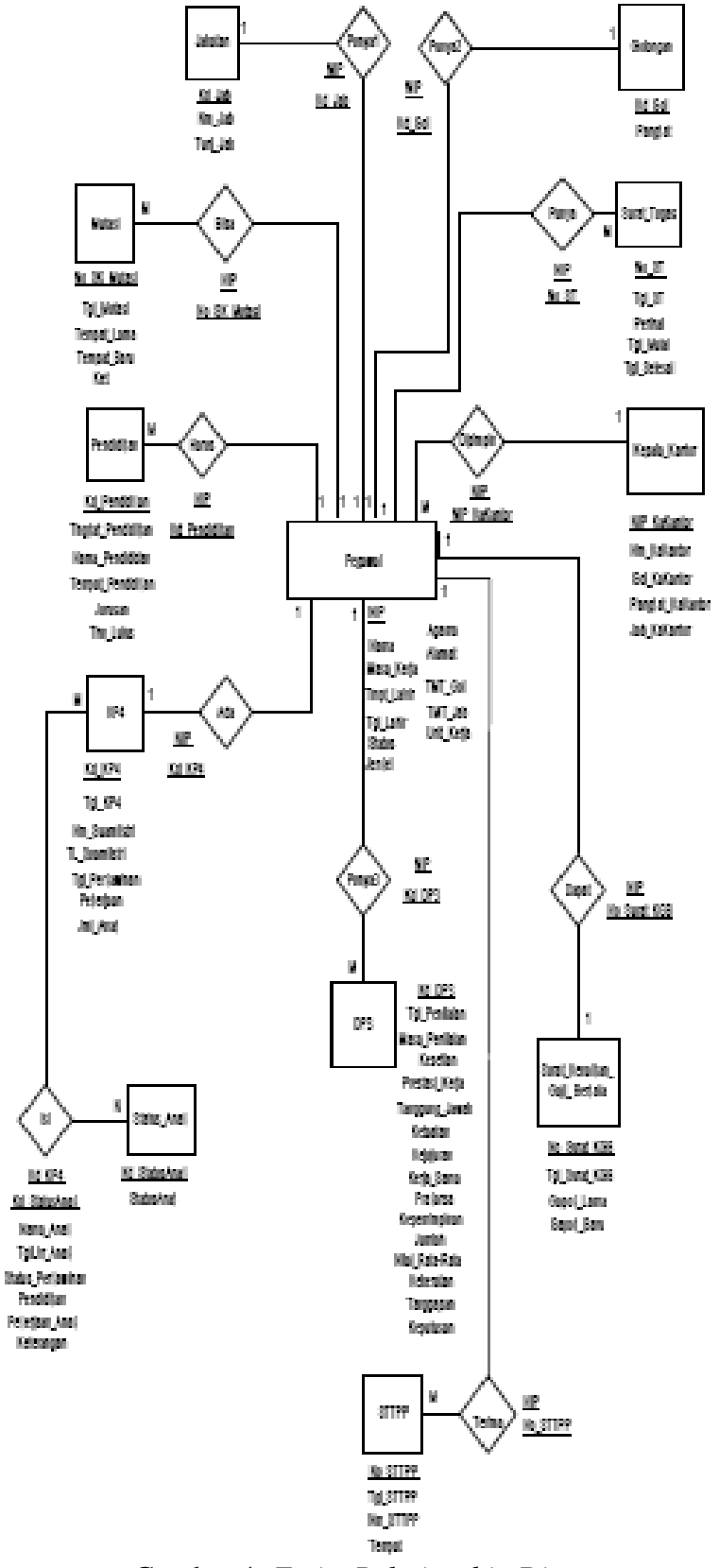

Gambar 4. Entity Relatiosnhip Diagram 
C. Struktur Tampilan

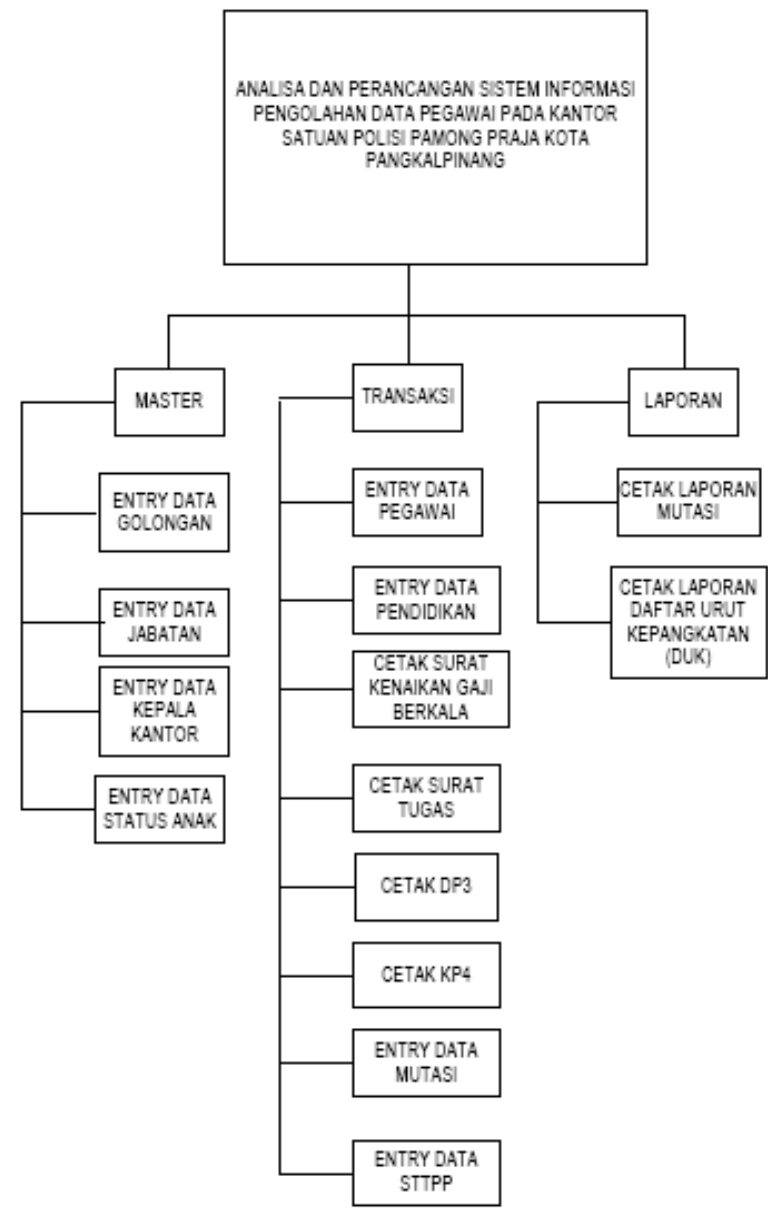

Gambar 5. Struktur Tampilan

D. Rancangan Layar

\section{1) Rancangan Layar Menu Utama}

\begin{tabular}{|lll}
\hline Menu Utama & & \\
\hline Master transaksI Laporan KelUar &
\end{tabular}

Gambar 6. Rancangan Layar Menu Utama
2) Rancangan Layar Entri Data Pegawai

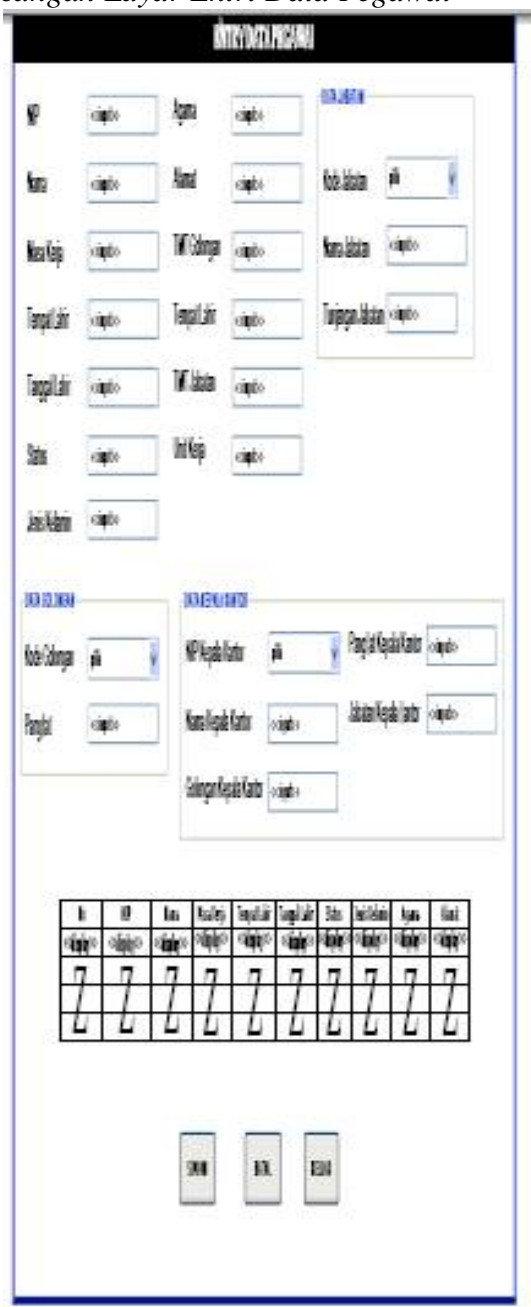

Gambar 7. Tampilan Layar Entry Data Pegawai

3) Rancangan Layar Cetak Surat Tugas

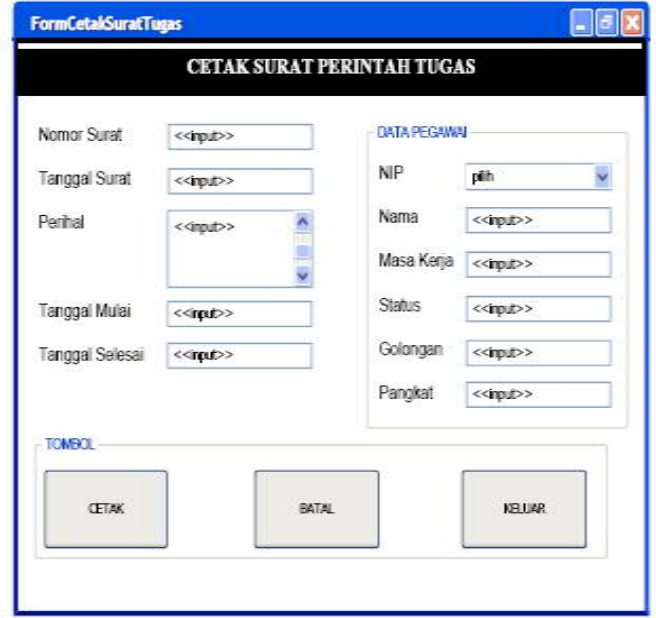

Gambar 8. Rancangan Layar Cetak Surat Tugas 
4)

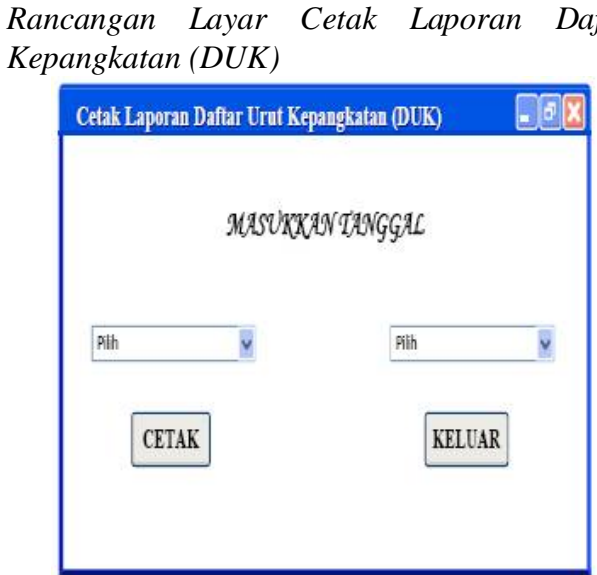

Gambar 9. Rancangan Layar Cetak Laporan Daftar Urut Kepangkatan (DUK)

\section{E. Sequence Diagram}

1) Sequence Diagran Entri Data Pegawai

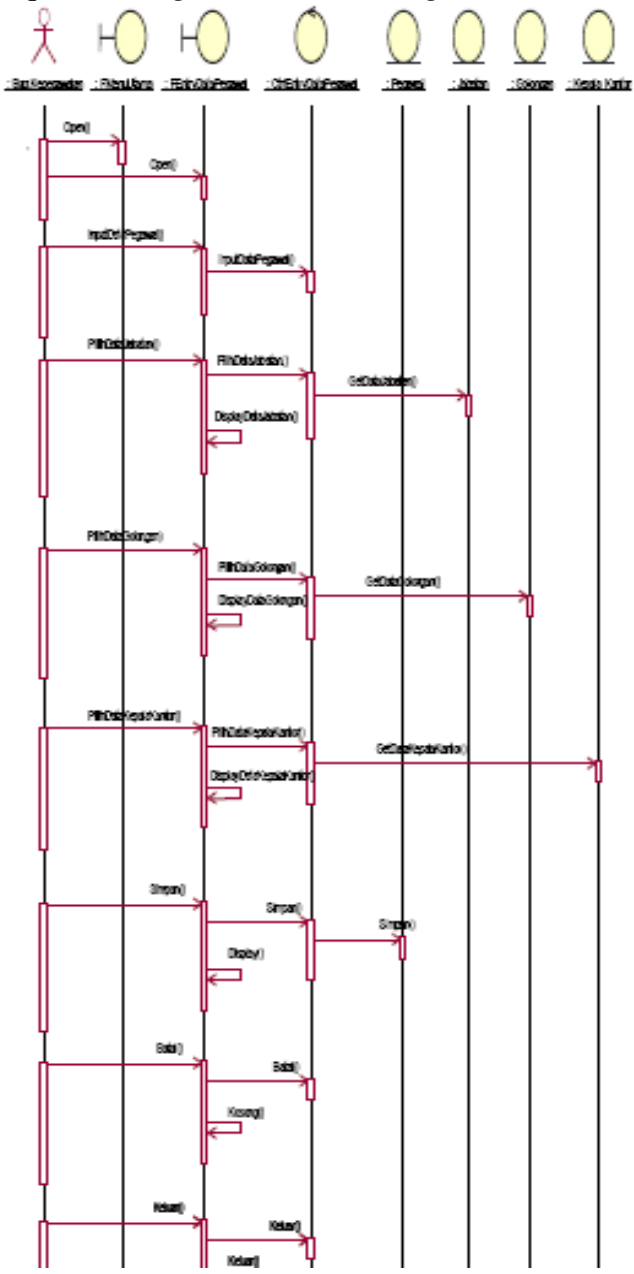

Gambar 10. Sequence Diagram Entri Data Pegawai
2) Sequence Diagram Cetak Surat Tugas

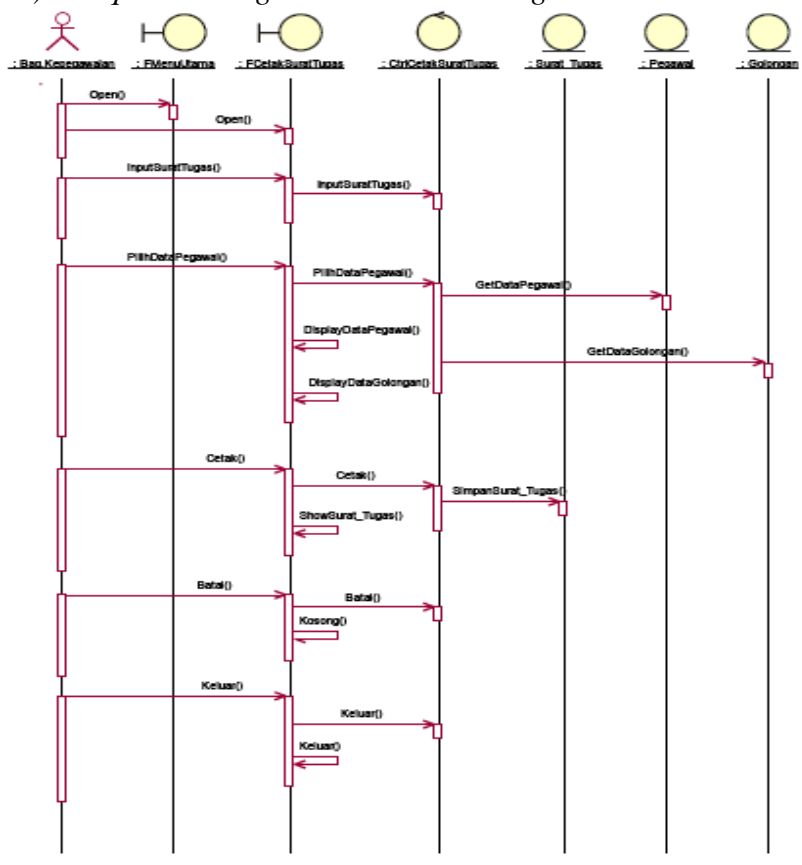

Gambar 11. Sequence Diagram Cetak Surat Tugas

3) Sequence Diagram Cetak Laporan Daftar Urut Kepangkatan $(D U K)$

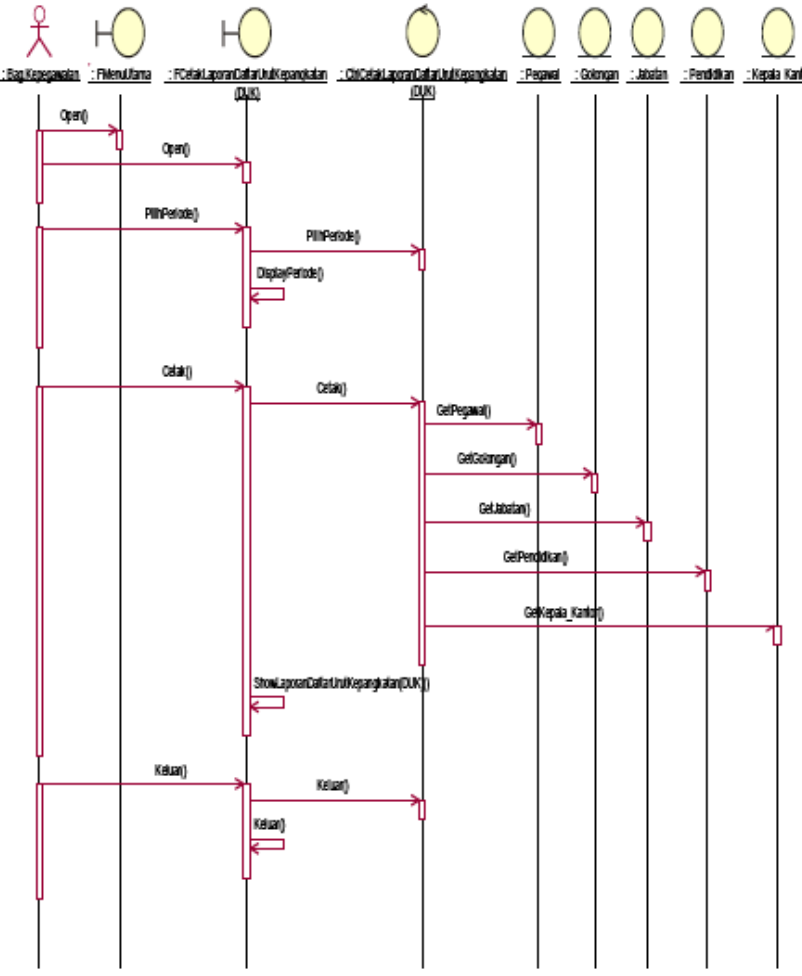

Gambar 12. Sequence Diagram Cetak Laporan Daftar Urut Kepangkatan 


\section{F. Class Diagram}

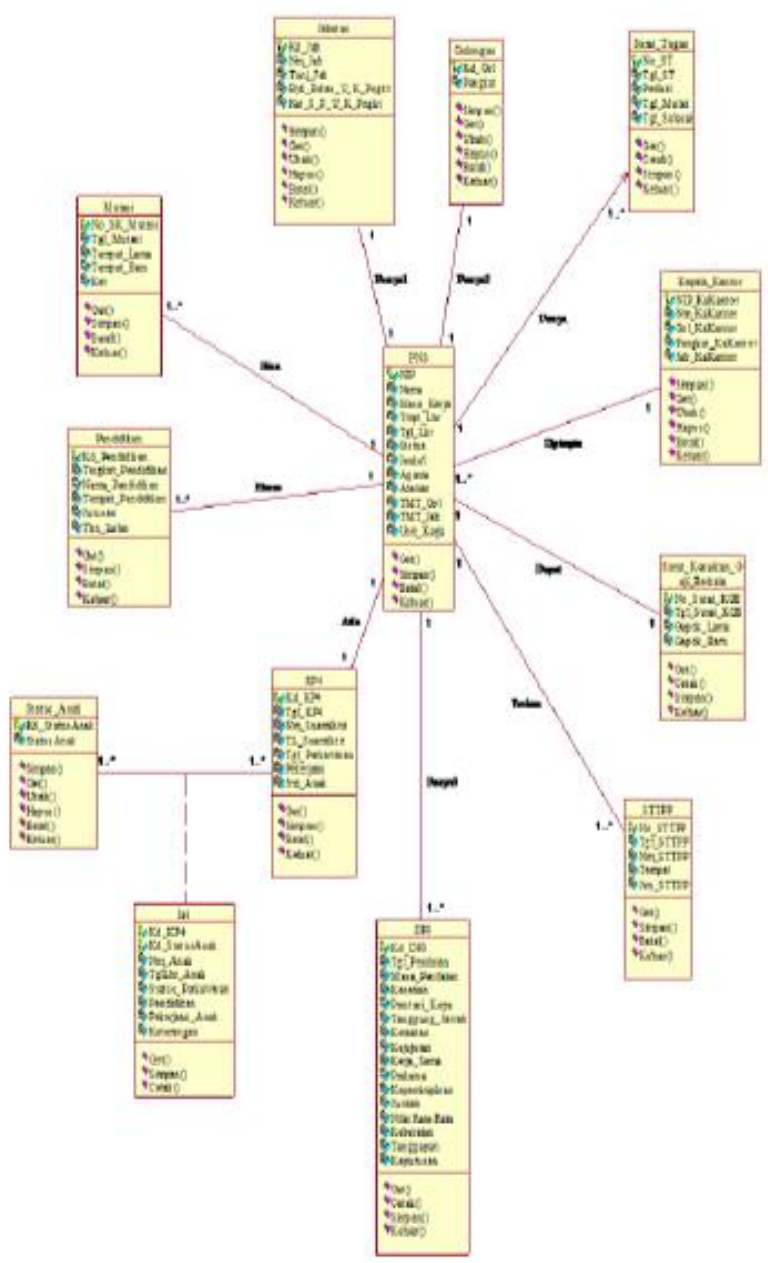

Gambar 13. Class Diagram

\section{PenUtuP}

\section{A. Kesimpulan}

Dari uraian yang telah dijelaskan pada bab-bab sebelumnya maka dapat diambil kesimpulan sebagai berikut :

- Dengan diterapkannya Analisa dan Perancangan Sistem Informasi Kepegawaian Pada Kantor Satuan Polisi Pamong Praja Kota Pangkalpinang berbasis Vb.Net, diharapkan dapat memberikan informasi yang cepat, tepat, dan akurat sesuai dengan kebutuhan.

- Mempermudah mengolah dan mengontol data kepegawaian .

- Meningkatkan efisiensi kerja karena pengolahan data dapat dilakukan dalam waktu yang lebih singkat dan dapat meminimalkan terjadinya kesalahan.

- Penyimpanan berkas pada sistem berjalan memerlukan banyak tempat, hal tersebut dapat diatasi dengan adanya Analisa dan Perancangan Sistem Informasi Keprgawaian Pada Kanror Satuan Polisi Pamong Praja Kota Pangkalpinang berbasis Vb.Net.

- Dari segi kecepatan proses ketepatan, pengontrolan, pengarsipan maupun dari segi penghematan waktu dan tenaga pada sistem yang yang terkomputerisasi ini lebih baik dari sistem manual.

\section{B. Saran}

Sehubungan dengan hal-hal tersebut di atas dan untuk meningkatkan keberhasilan Analisa dan Perancangan Sistem Informasi Pengolahan Data Pegawai Pada Kantor Satuan Polosi Pamong Praja Kota Pangkalpinang berbasis Vb.Net, maka berikut ini adalah saran-saran agar program dapat berjalan dengan lebih efektif, yaitu :

- Diperlukan pelatihan terhadap sumber daya manusia yang sudah ada untuk mendukung keberhasilan sistem ini.

- Diperlukan adanya back up data untuk mencegah hal-hal yang tidak diinginkan.

- Sistem yang baru perlu ditunjang dengan pemeliharaan yang baik agar dapat berjalan sesuai dengan tujuannya.

- Koordinasi yang baik dapat menentukan keberhasilan sistem ini.

\section{DAFTAR PUSTAKA}

[1] Aji Supriyanto, Pengantar Tekhnologi Informasi. Semarang: Salemba Infotek, 2005.

[2] Albahra bin Lajmudin, Analisis dan Desain Sistem Informasi. Tangerang: Graha Ilmu, 2005.

[3] Ariesto hadi Sutopo, Analisis dan Desain Berorientasi Objek. Jakarta :J\&.J Learning, 2002.

[4] Jeffery L, Whitten et al, Perancangan sistem berorientasi Obyek. Bandung: Informasi, 2004. 